\title{
Technique and nuances of an S-2 alar iliac screw for lumbosacral fixation in patients with transitional and normal anatomy
}

\author{
Junichi Ohya, MD, ${ }^{1}$ Todd D. Vogel, MD, ${ }^{1}$ Sanjay S. Dhall, MD, ${ }^{1}$ Sigurd Berven, MD, ${ }^{2}$
} and Praveen V. Mummaneni, MD'

Departments of ${ }^{1}$ Neurological Surgery and ${ }^{2}$ Orthopedic Surgery, University of California, San Francisco, California

\begin{abstract}
S-2 alar iliac (S2Al) screw fixation has recently been recognized as a useful technique for pelvic fixation. The authors demonstrate two cases where S2AI fixation was indicated: one case was a sacral insufficiency fracture following a longsegment fusion in a patient with a transitional S-1 vertebra; the other case involved pseudarthrosis following lumbosacral fixation. S2AI screws offer rigid fixation, low profile, and allow easy connection to the lumbosacral rod. The authors describe and demonstrate the surgical technique and nuances for the S2Al screw in a case with transitional S-1 anatomy and in a case with normal S-1 anatomy.
\end{abstract}

The video can be found here: https://youtu.be/Sj21lk13_aw.

KEYWORDS S-2 alar iliac screw; revision surgery; stereotactic navigation; video 